\title{
Estimation of the reaction time of the driver of a two-wheeled vehicle in case of danger
}

\author{
Sergey Evtyukov ${ }^{l}$, Ilya Brylev ${ }^{l}$ and Maria Blinder ${ }^{1 *}$ \\ ${ }^{1}$ Saint Petersburg State University of Architecture and Civil Engineering, Saint Petersburg, Russia
}

\begin{abstract}
The author's team analyzed a bicycle as a two-wheeled vehicle. (TWV) The purpose of the study was to estimate the parameters affecting the reaction time of the cyclist. Depending on the type of brake system, the mass of the two-wheeled vehicle and the cyclist, the speed, and the bicycle designs graphs were built, and their analysis was carried out. Based on the test results, factors affecting the cyclist reaction time in case of danger were disclosed.
\end{abstract}

\section{Introduction}

Bicycle, according to the Traffic rules 2021 [14] - a vehicle that has at least two wheels and is driven as a rule of muscular energy of persons on this vehicle, in particular with the help of pedals or handles, and may also have The motor with a nominal maximum power in a long-term load mode not exceeding $0.25 \mathrm{~kW}$, automatically disconnected at speeds of more than $25 \mathrm{~km} / \mathrm{h}$. From year to year the number of accidents involving cyclists increases. The establishment of objective causes of violation of traffic rules, and circumstances conducive to it, is one of the important tasks for a more detailed reconstruction and expertise of an accident with bicycles. [1,2].

The diagram (Fig. 1) show the number of accidents involving cyclists by months in 2020 in Russian Federation according to the official Site of the State Traffic Inspectorate [13].

\footnotetext{
* Corresponding author: maria.blinder@mail.ru
} 


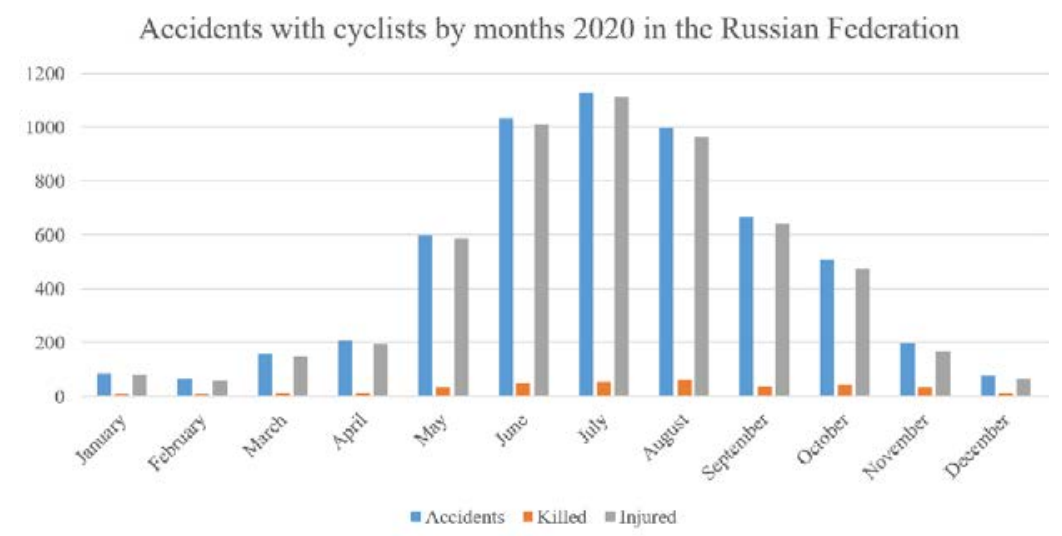

Fig. 1. Dynamics of road traffic accidents involving cyclists in 2020 in RF (people)

Compared to the last 2019 year, the increase of the number of victims and killed people is traced mainly in the European part of the country in Vladimirsky, Tambovsky, Tulsky, Kursky regions, but the increase in the number of accidents in the Krasnodarsky region is strongly noticeable (Fig. 2), as well as in big cities, such as Moscow (2019 ye. - 237 accidents, 2020 ye. - 357 accidents), St. Petersburg (2019 ye. - 305 accidents, 2020 ye. 352 accidents). This is due to the growing popularity of bicycles in these regions.

Accidents with cyclists by months 2020 in Krasnodarsky region

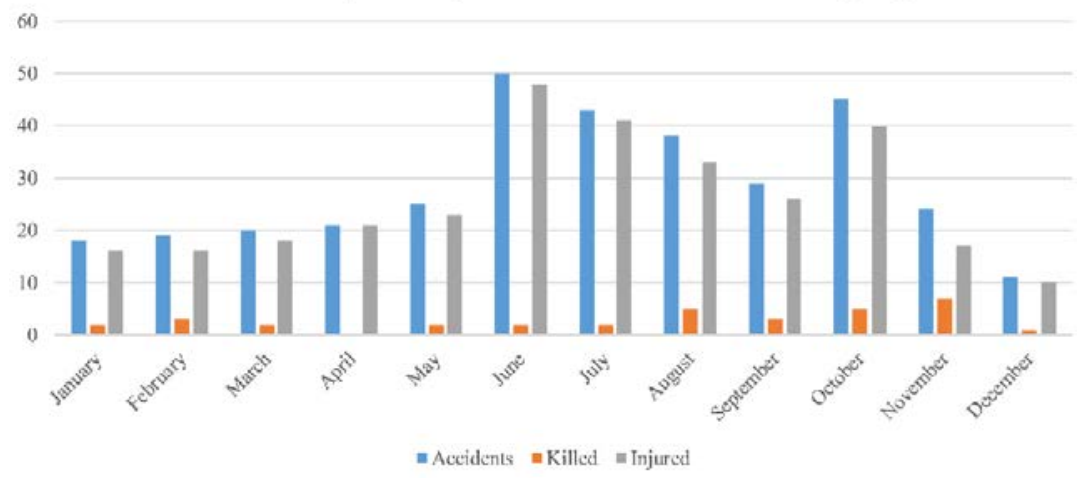

Fig. 2. Dynamics of road traffic accidents involving cyclists in 2020 in Krasnodarsky region (p)

The distance necessary for a complete stop of the stop, as well as the driver reaction time is the most important parameters for the reconstruction and expertise of an accident with bicycles. [11,12].

The purpose of this study is to determine the distance necessary for a complete stop of the bicycle in case of danger, as well as the reaction time of the cyclist. Cases where the bicycle driver awaits danger and is ready to apply emergency braking (driver's hands on brakes: front and back, and legs on pedals).

\section{Material and methods}

On the experimental base of the Department of road traffic faculty SPbGASU by the author's team with the help of the deselerometer model 'LWS-2MC', the steady-state deceleration and Rise time deceleration of two-wheeled vehicle were determined [16]. 
6 cyclists were involved in the experiment. A monitor operating on the following principle was installed before the two-wheeled vehicle - when the red light on the monitor was replaced by a green, then the driver sitting on a two-wheeled vehicle was to activate both brakes as quickly as possible. The measurement began with the moment when the red light was replaced by green, and ended when the test was used in braking, then the values when applying combination braking were automatically transferred to the central database. TWV drivers were to perform braking in ready mode. Apply braking, trying to simultaneously press the front and rear bike brake. The readiness mode means that the driver was already ready for braking, that is, the driver placed his hands in advance on the brakes. The result of zero seconds $(0 \mathrm{~s})$ was automatically recorded if the driver activated the front or rear brake lever before the indicator was changed to the green, or if the driver forgot to activate one or another lever, these results were excluded from statistical analysis $[4,5]$.

\section{Theory / calculation}

The reaction time of the TWV driver (cyclist) is the time required by the cyclist to see the danger in front - realize the danger - make the decision to slow down, and then respond to danger by pressing the brakes (Table 1) [6].

Table 1. Components of the reaction time of the cyclist (in sec.)

\begin{tabular}{|c|c|c|}
\hline Name & Decipher & $\begin{array}{c}\text { Experimentally } \\
\text { established }\end{array}$ \\
\hline$t_{0}$ & $\begin{array}{c}\text { Danger detection } \\
\text { time }\end{array}$ & $0,20-0,35$ \\
\hline$t_{6}$ & $\begin{array}{c}\text { Perception time } \\
\text { (awareness) }\end{array}$ & $0,50-0,70$ \\
\hline$t_{6}$ & $\begin{array}{c}\text { Reaction decision } \\
\text { making time }\end{array}$ & $0,60-0,75$ \\
\hline$t_{m}$ & $\begin{array}{c}\text { Time to make a } \\
\text { decision about } \\
\text { braking method } \\
\text { (front, rear or both) }\end{array}$ & $0,15-0,25$ \\
\hline$t_{c}$ & $\begin{array}{c}\text { Time to compress } \\
\text { hands brushes }\end{array}$ & $0,17-0,25$ \\
\hline
\end{tabular}

The cyclist reaction time consists of a number of components:

$$
T_{l=} t_{0}+t_{b}+t_{p}+t_{m}+t_{c}
$$

where $t_{0}$ - danger detection time, $t_{6}$ - perception time (awareness), $t_{p}$ - reaction decision making time, $t_{m}$ - time to make a decision about braking method (front, rear or both), $t_{c}$ time to compress hands brushes.

The distance that TWV is held to a complete stop consists of a distance that the bike passes from the beginning of the driver detection of a dangerous situation until the TWV full stop [3].

Parameters affecting the distance of full braking of the bicycle:

- speed

- bicycle / cyclist weight $=$ mass

- bike brake ability

- road surface

- cyclist reaction time 
It is worth noting that on a two-wheeled vehicle during emergency braking, the driver cannot instantly apply braking until it stops. First of all, the driver needs to start a partial braking to have time to move the body weight (body weight should be moved back). If the driver of the TWV applies sharp braking immediately without transferring body weight back, there is a huge chance to fall $[7,8]$.

The distance requested a bike for a complete stop can be calculated by the formula:

$$
S=S_{1}+S_{2}
$$

where $S_{1}$ - distance that the bike passes from the beginning of the driver detection of a dangerous situation, $S_{2}$ - distance from the start of braking to the full stop.

$$
\begin{gathered}
S 1=V^{*} T_{1} \\
S_{2}=V^{2} /(2 * J)
\end{gathered}
$$

where $\mathrm{V}$ - the speed of the cyclist, $\mathrm{m} / \mathrm{s}, \mathrm{S}$ - the distance of the full stop of TWV, $\mathrm{m}, \mathrm{J}$ - the steady-state deceleration of $\mathrm{TWV}, \mathrm{m} / \mathrm{s}^{2}$.

\section{Results and discussion}

Table 2 shows the characteristics of bicycles with different materials of the frames, the types of the brake system, suspension, TWV geometry and its purpose and cyclists with different mass.

Table 2. Characteristics of bicycles and cyclists

\begin{tabular}{|c|c|c|c|c|c|}
\hline Bicycle & $\begin{array}{c}\text { Bicycle Mass } \\
(\mathbf{k g})\end{array}$ & Brake Type & Type or bycicle & $\begin{array}{c}\text { Driver } \\
\text { mass } \\
\mathbf{( k g})\end{array}$ & $\begin{array}{c}\text { Full } \\
\text { mass } \\
\text { (kg) }\end{array}$ \\
\hline Diamondback & 13,6 & Shimano 105 & Mountain bike & 90,1 & 103,7 \\
\hline Mongoose & 12,1 & $\begin{array}{c}\text { Shimano BR- } \\
\text { M400 }\end{array}$ & Mountain bike & 69,1 & 81,2 \\
\hline Cannondale & 7,9 & Shimano 105 & Road bike & 68,3 & 73,2 \\
\hline GT & 12,0 & SRAM Level TL & Mountain bike & 75,0 & 87,0 \\
\hline Merida & 11,4 & $\begin{array}{c}\text { TRP Spyre } \\
\text { Flatmount }\end{array}$ & Road bike & 71,2 & 82,6 \\
\hline Specialized & 9,4 & $\begin{array}{c}\text { Shimano BR- } \\
\text { MT200 }\end{array}$ & Mountain bike & 96,6 & 106 \\
\hline
\end{tabular}

Tables 3-5 shows the results of the TWV braking tests the total distance of braking at various speed of bicycle $(10 \mathrm{~km} / \mathrm{h}, 15 \mathrm{~km} / \mathrm{h}, 20 \mathrm{~km} / \mathrm{h})$ and driver reaction time for each specific case when using combined braking method and skid-resistance coefficient $=0.7$ (dry asphalt). 
Table 3. Tests for braking from $10 \mathrm{~km} / \mathrm{h}$, conducted on a smooth dry asphalt.

\begin{tabular}{|c|c|c|c|}
\hline Bicycle & $\begin{array}{c}\text { Steady-state } \\
\text { deceleration } \mathbf{( j )}, \mathbf{m} / \mathbf{s}^{\mathbf{2}}\end{array}$ & $\begin{array}{c}\text { Braking distance } \\
\text { from speed } \\
\mathbf{1 0} \mathbf{~ k m} / \mathbf{h}, \mathbf{m}\end{array}$ & $\begin{array}{c}\text { Driver reaction time, } \\
\mathbf{s}\end{array}$ \\
\hline Diamondback & 4,9 & 7,73 & 2,50 \\
\hline Mongoose & 5,1 & 7,67 & 2,49 \\
\hline Cannondale & 5,0 & 7,22 & 2,32 \\
\hline GT & 5,4 & 7,58 & 2,47 \\
\hline Merida & 5,5 & 6,76 & 2,18 \\
\hline Specialized & 5,6 & 6,36 & 2,04 \\
\hline Average values & $\mathbf{5 , 2 5}$ & $\mathbf{7 , 2 2}$ & $\mathbf{2 , 3 2}$ \\
\hline
\end{tabular}

Table 4. Tests for braking from $15 \mathrm{~km} / \mathrm{h}$, conducted on a smooth dry asphalt.

\begin{tabular}{|c|c|c|c|}
\hline Bicycle & $\begin{array}{c}\text { Steady-state } \\
\text { deceleration } \mathbf{( j )}, \mathbf{m} / \mathbf{s}^{\mathbf{2}}\end{array}$ & $\begin{array}{c}\text { Braking distance } \\
\text { from speed } \\
\mathbf{1 5} \mathbf{~ k m} / \mathbf{h}, \mathbf{~ m}\end{array}$ & $\begin{array}{c}\text { Driver reaction time, } \\
\mathbf{s}\end{array}$ \\
\hline Diamondback & 4,9 & 12,23 & 2,51 \\
\hline Mongoose & 5,1 & 12,08 & 2,45 \\
\hline Cannondale & 5,0 & 12,11 & 2,49 \\
\hline GT & 5,4 & 11,40 & 2,35 \\
\hline Merida & 5,5 & 10,37 & 2,11 \\
\hline Specialized & 5,6 & 9,93 & 2,01 \\
\hline Average values & $\mathbf{5 , 2 5}$ & $\mathbf{1 1 , 3 5}$ & $\mathbf{2 , 3 2}$ \\
\hline
\end{tabular}

Table 5. Tests for braking from $10 \mathrm{~km} / \mathrm{h}$, conducted on a smooth dry asphalt.

\begin{tabular}{|c|c|c|c|}
\hline Bicycle & $\begin{array}{c}\text { Steady-state } \\
\text { deceleration } \mathbf{( j )}, \mathbf{m} / \mathbf{s}^{\mathbf{2}}\end{array}$ & $\begin{array}{c}\text { Braking distance } \\
\text { from speed } \\
\mathbf{2 0} \mathbf{~ k m} / \mathbf{h}, \mathbf{~ m}\end{array}$ & $\begin{array}{c}\text { Driver reaction time, } \\
\mathbf{s}\end{array}$ \\
\hline Diamondback & 4,9 & 16,98 & 2,49 \\
\hline Mongoose & 5,1 & 16,97 & 2,51 \\
\hline Cannondale & 5,0 & 16,81 & 2,47 \\
\hline GT & 5,4 & 15,97 & 2,36 \\
\hline Merida & 5,5 & 15,53 & 2,29 \\
\hline Specialized & 5,6 & 14,48 & 2,11 \\
\hline Average values & $\mathbf{5 , 2 5}$ & $\mathbf{1 6 , 1 2}$ & $\mathbf{2 , 3 8}$ \\
\hline
\end{tabular}

Based on the experimental results for each TWV graphs of the dependence of the TWV braking distance from the steady-state deceleration and the bicycle speed were constructed (Fig. 3), and polynomial regression equations were also obtained. 


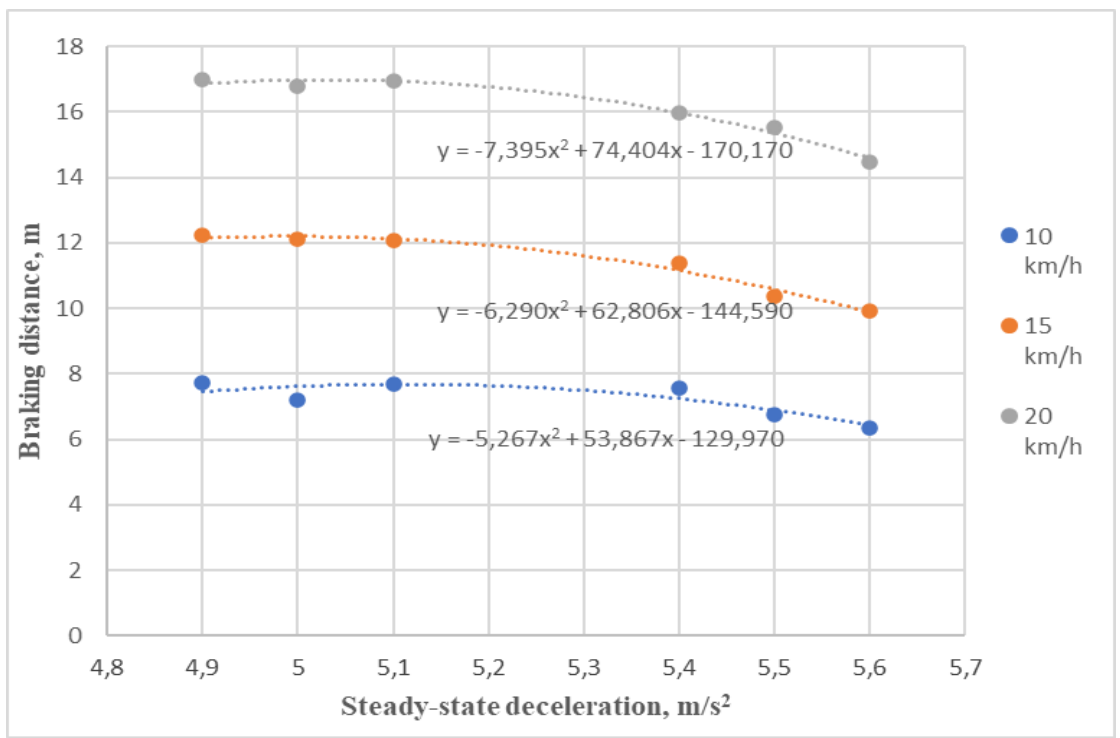

Fig. 3. Dependence of TWV braking distance from steady-state deceleration and TWV speed.

The regression equation when braking from a speed of $10 \mathrm{~km} / \mathrm{h}$ is calculated by the formula:

$$
y=-7,395 x^{2}+74,404 x-170,170
$$

where $x$ - is the steady-state deceleration, $\mathrm{m} / \mathrm{s}^{2} ; y$ - bicycle braking distance, $\mathrm{m}$

The regression equation when braking from a speed of $10 \mathrm{~km} / \mathrm{h}$ is calculated by the formula:

$$
y=-6,290 x^{2}+62,806 x-144,590
$$

where $x$ - is the steady-state deceleration, $\mathrm{m} / \mathrm{s}^{2} ; y$ - bicycle braking distance, $\mathrm{m}$

The regression equation when braking from a speed of $10 \mathrm{~km} / \mathrm{h}$ is calculated by the formula:

$$
y=-5,267 x^{2}+53,867 x-129,970
$$

where $x$ - is the steady-state deceleration, $\mathrm{m} / \mathrm{s}^{2} ; y$ - bicycle braking distance, $\mathrm{m}$

The practical significance of the regression equations is the possibility of their use in order to determine the driver's reaction time on the basis of the braking distance and the steady-state deceleration of TWV $[9,10]$.

The processing of the results of experimental studies made it possible to obtain the range of values of the reaction time of the cyclists, as well as set the average reaction time (Fig. 4). 


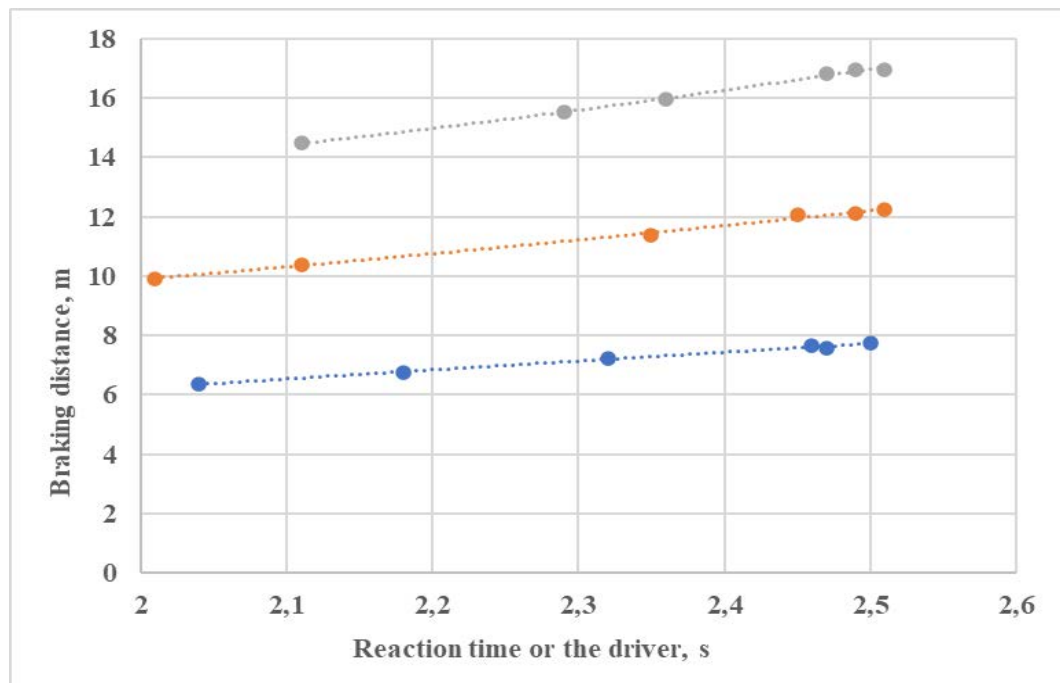

Fig. 4. Range of values of the reaction time of the cyclists

The range of values of the response of the driver of the TWV (cyclist) is in the range of from 2,0-2,5 s, and the average value is $2,34 \mathrm{~s}$ from which it can be concluded that it is needed to make more accurate determination of the driver's reaction time for each specific accident.

In conclusion the result of the study shows that the braking distance of the cyclist depends on the speed of the bicycle. The resulting reaction time differs from the universal previously adopted in the work of Pushkin V. A. [15], which indicate that more detailed study of the parameters required to carry out a more accurate expertise of the accident with cyclists. The results obtained in experiment can be a step towards a more accurate auto technical expertise of an accident with bicycles.

\section{References}

1. I.S. Brylev, Experimental studies of the parameters of the deceleration of vehicles category L3 / Bulletin of civil engineers SPbGASU / №2 (49), - p. 131-137 (2015)

2. S.A. Evyukov, V.A. Puchkin, Forensic autotechnical expertise of an accident/ ID Petropolis p.416 (2017)

3. G.V. Sukhodolsky Engineering and psychological expertise of road accidents X.: Publishing house Humanitarian Center, p. 156 (2006)

4. G. Ginzurg, S.A. Evyukov, I.S. Brylev, S.A. Volkov, Reconstruction of Road Accidents Based on Braking Parameters of Category L3 Vehicles // Transportation research procedia volume 20, p. 212-218 (2017)

5. S.A. Evyukov, I.S. Brylev, Problems of conducting car vehicles with motorcyclists / Fundamental and applied sciences Northcharleston, SC, USA - p.125-129 (2013)

6. Guide for the development of bicycle facilities // American association of state highway and transportation officials - № 3(50). - 1999. - p.39-49;

7. S.A. Evyukov, I.S. Brylev, Overview of existing methods for calculating the speed of two-wheeled vehicles // Modern problems of science and education. № 6 (2013) 
8. S.A. Evyukov, I.S. Brylev, M.M. Blinder, Reconstruction of a road accident and an assessment of the injuries of a cyclist obtained from a collision of a two-wheeled vehicle with a car - Tyumen: Tiu p.3 (2021)

9. S.A. Evyukov, I.S. Brylev, Estimated assessment of the parameters of the process of braking vehicles of category L3 during the reconstruction of an accident / Bulletin of civil engineers SPbgas №2 (55), - P. 181-185 (2016)

10. S.A. Evyukov, I.S. Brylev, Problems of calculating the speed of movement of twowheeled mechanical vehicles at an accident, Transportation Research Procedia 36, $\mathrm{p}$. 84-89 (2018)

11. E. Kurakina, S.A. Evyukov, Results of studying road construction parameters condition. Architecture and Engineering 3. № 1 p. 29-37 (2018)

12. Official website of the Ministry of Internal Affairs of the Russian Federation, the traffic police of Russia [Electronic resource] URL: http://stat.gibdd.ru (2021)

13. Traffic Rules 2021 (last change on December 31, 2020) - St. Petersburg, p.96 (2021)

14. V.A. Puchkin, Basics of expert analysis of road traffic accidents: databases. Expert technique. Methods of solutions. - Rostov N / D: IPO Yufu - P. 181-192 (2010)

15. Evtyukov C.A., Brylev I. S., Blinder M.M. Factors affecting the formation of a steadystate deceleration of two-wheeled vehicles/ Bulletin of civil engineers. - St. Petersburg: SPbgas No. 6 (83) P. 186-195 (2020) 